\title{
An early fault detection approach in grid-connected photovoltaic (GCPV) system
}

\author{
N. Muhammad ${ }^{1}$, H. Zainuddin ${ }^{2}$, E. Jaaper ${ }^{3}$, Z. Idrus ${ }^{4}$ \\ ${ }^{1,2,3}$ Faculty of Applied Sciences, Universiti Teknologi MARA, Malaysia \\ ${ }^{4}$ Faculty of Computer and Mathematical Sciences, Universiti Teknologi MARA, Malaysia
}

\begin{tabular}{l} 
Article Info \\
\hline Article history: \\
Received May 26, 2019 \\
Revised Jun 27, 2019 \\
Accepted Jul 11, 2019 \\
\hline
\end{tabular}

Keywords:

Acceptance ratio

AC power

Fault detection

Grid-connected

Photovoltaic system

\begin{abstract}
Faults in any components of PV system shall lead to performance degradation and if prolonged, it can leads to fire hazard. This paper presents an approach of early fault detection via acquired historical data sets of gridconnected PV (GCPV) systems. The approach is a developed algorithm comprises of failure detection on AC power by using Acceptance Ratio (AR) determination. Specifically, the implemented failure detection stage was based on the algorithm that detected differences between the actual and predicted AC power of PV system. Furthermore, the identified alarm of system failure was a decision stage which performed a process based on developed logic and decision trees. The results obtained by comparing two types of GCPV system (polycrystalline and monocrystalline silicon PV system), showed that the developed algorithm could perceive the early faults upon their occurrence. Finally, when applying AR to the PV systems, the faulty PV system demonstrated $93.38 \%$ of AR below 0.9 , while the fault free PV system showed only $31.4 \%$ of AR below 0.9 .
\end{abstract}

Copyright (C) 2020 Institute of Advanced Engineering and Science. All rights reserved.

\section{Corresponding Author:}

H. Zainuddin,

Faculty of Applied Sciences,

Universiti Teknologi MARA,

40450 Shah Alam, Selangor Darul Ehsan, Malaysia.

Email: zainuddinhedzlin@gmail.com

\section{INTRODUCTION}

The solar industry has grown rapidly over the past few years. The momentum of the growth is represented by the number and capacity of Photovoltaic (PV) system installations all over the world [1]. The effectiveness of PV system operational can be influenced by several circumstances which may results in power loss and waste [2]. Fault detection methods are significant to increase the performance, reliability and avoiding loss of income generation. Faults or abnormalities that presence in the system could be the factor that led to the low performance of the PV system. The faults which could be originated from AC or DC side should be identified in order to clarify the actual or exact positions of faults and could avoid the equipment damage and consequently the labor's safety [3]. The ability to detect and diagnose potential failures at an early stage or before occurrence is also crucial to reduce costs associated with operation, maintenance and system downtime.

Various studies of fault detection were seriously focused. These studies include the fault finding by using mathematical method diagnosis [4], evaluating performance ratio (PR), capture losses, array and grid power losses analysis [1] and also artificial neural network [5]. Numerous fault detection techniques on DC side of PV system have been applied; such as climatic data independent technique (CDI) [6], electrical current-voltage (I-V) measurement (EM) technique [7], measured and modeled PV system outputs (CMM) technique [8], power loss analysis (PLA) technique [9], Machine learning (ML) techniques [10, 11], 
heat exchange and temperature (HET) based models [12], ground fault detection and interruption (GFDI) fuse [12], residual current monitoring devices (RCDs) [12], insulation monitoring devices (IMDs) [13], frequency spectrum analysis (FSA) of the voltage or current waveforms [13], estimating randomness in the voltage signal (ERV) [13], spread spectrum time-domain reflectometry (SSTDR), infrared (IR)/ thermal imaging [14], visual inspection and lock in thermography (LIT) [13]. Furthermore, fault detection techniques on AC side consists of fault detection technique for converter [15, 16] and islanding detection technique [17, 18]. Acceptance Ratio (AR) is one of the parameters that used from recent studies to detect fault in the PV system. Acceptance ratio is defined as the ratio of the actual AC power output to expected AC power output. However, in Malaysia, AR has still not yet been extensively studied in addressing early fault detection.

This study is designed to develop early fault detection approach, aiming to maximize the GCPV system's operational performance. For this purpose, the actual AC Power $\left(\mathrm{P}_{\mathrm{AC} \_ \text {actual }}\right)$ and expected AC power $\left(P_{A C_{-} \text {expected }}\right)$ of two different GCPV systems of monocrystalline and polycrystalline were analysed. An evaluation of the AR for the two GCPV systems was conducted to diagnose fault at early stage.

\subsection{Acceptance Ratio (AR)}

AR is generally defined as the ratio of actual AC power to expected AC power. Sustainable Energy Development Authority of Malaysia (SEDA) has set a threshold value of AR in addressing acceptance of an installed and operating PV system. If the value of AR is equal or larger than 0.9, the system is said to be an accepted operating PV system. In other words, the system is identified as having no fault [19].

The following equations are needed in order to calculate AR for a GCPV system [19].

$$
\begin{aligned}
& A R=\frac{P_{\text {AC_Actual }}}{P_{\text {AC_Expected }}} \\
& P_{A C_{\text {expected }}}=P_{\text {array_STC }} \times k_{g} \times k_{\text {temp }} \times k_{m m} \times n_{\text {inv }} \times n_{\text {cable }} \times k_{\text {dirt }} \times k_{\text {age }}
\end{aligned}
$$

and,

$$
\begin{aligned}
& k_{g}=\frac{G}{1000} \\
& k_{\text {temp }}=1+\left[\left(\frac{\delta}{100}\right) \times\left(T_{\text {cell }}-T_{\text {stc }}\right)\right.
\end{aligned}
$$

Where, $P_{A C_{-} \text {actual }}$ is actual AC Power, $P_{A C_{-} \text {expected }}$ is expected AC Power, $P_{\text {array_STC }}$ is the peak power of the PV array at STC, $k_{g}$ is peak sun factor (decimal), $k_{\text {temp }}$ is de-rating factor of power due to cell temperature, $k_{m m}$ is the de-rating factor due to module mismatch, $\eta_{i n v}$ is the efficiency of inverter and $\eta_{\text {cable }}$ is the efficiency of cables, $k_{\text {dirt }}$ is the derating factor due to dirt and $k_{\text {age }}$ is the derating factor due to aging of the PV module. While $G$ is the plane of array irradiance, $T_{\text {cell }}$ is the cell effective temperature and $T_{s t c}$ is the cell temperature at STC (provided in data sheet).

A comparison study was conducted on AR as a function of irradiance for two GCPV systems in Kuala Lumpur, Malaysia. The study showed that for a normal PV system, the ARs were scattered dominantly above 0.9 and the rest were below 0.9 down to 0.65 as the irradiance increases. However for faulty PV system, it was found that ARs were scattered dominantly below 0.9 down to 0.2 . This study also verified the result by cross checking with performance ratio (PR) indices and highlighted that AR could be an early fault detection tool to determine whether the PV system is in faulty or normal condition [4]. Another similar study was also conducted on a $1.1 \mathrm{kWp}$ GCPV system in Shah Alam, Malaysia. The study also included comparison between real operating field data and data declared by the manufacturer [20].

Khatri and Kumar also stated that the faults in PV system can be diagnosed by comparing the actual electrical parameters with the expected electrical parameters, in which these parameters are dependable on the system configuration parameters and meteorological data [1,21]. Typically, comparison of the measured data against simulation results is also accepted as one of the examination method for fault detection in PV system. Other study reported fault detection through comparison between the simulated and measured data of the string powers. This technique also helps to identify the short and open circuit of PV modules in a PV string [22]. 


\section{RESEARCH METHODOLOGY}

The research methodology applied in this study encompasses two sections of PV systems descriptions and fault analytical approach.

\subsection{PV System Description}

Two GCPV systems of polycrystalline and monocrystalline were chosen in this study to address early fault detection investigation. The capacities of the polycrystalline and monocrystalline GCPV systems are $5.405 \mathrm{kWp}$ and $9 \mathrm{kWp}$ respectively. Both systems were installed and commissioned in April 2012. The systems are located at Green Energy Research Center (GERC) test site of the Universiti Teknologi MARA (UiTM) Shah Alam (3 04'08.70'North latitude and 101 ${ }^{\circ} 29^{\prime}$ '49.66” East longitude).

The polycrystalline system comprises 23 unit of PV modules rated at $235 \mathrm{~W}_{\mathrm{p}}$, meanwhile the monocrystalline system comprises 36 unit of PV modules rated at $250 \mathrm{~W}_{\mathrm{p}}$. The systems were installed on the parking rooftop at $10^{\circ}$ angle of inclination and mounting arrangement due to South-East as shown in Figure 1. The performance of each PV system and the prevailing meteorological conditions were recorded according to the requirements set by the international standard of IEC 61724 [23].

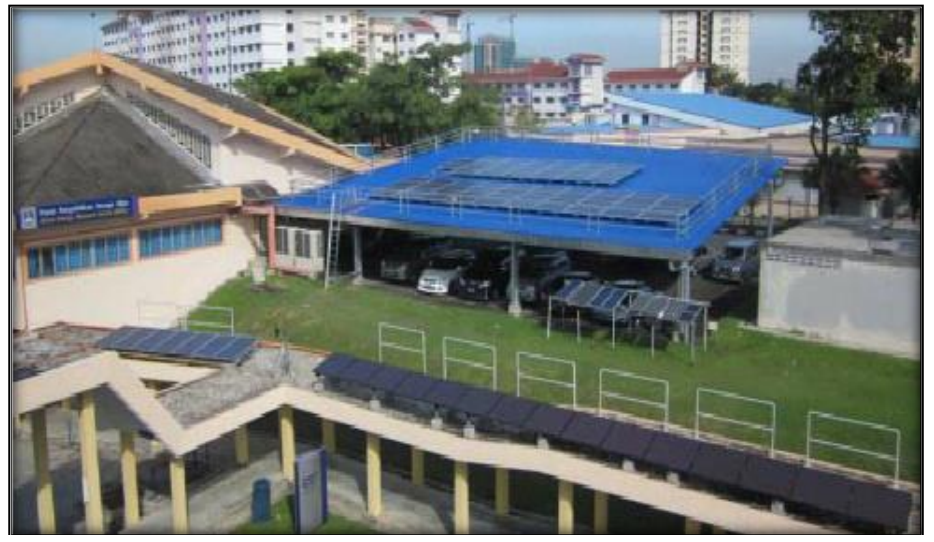

Figure 1. GCPV system test site at GERC, UiTM Shah Alam, Malaysia

\subsection{Fault Analytical Approach}

In this study, the fault analytical approaches for early detection were divided into two stages. The first failure detection stage is based on algorithm that detected inconsistencies between the actual AC power and predicted AC power. Accordingly, the comparison of $P_{\text {ac_expected }}$ and $\mathrm{P}_{\text {ac_actual }}$ were used to analyze the detected fault by using the logic and decision tree as shown in Figure 2 and Figure 3 respectively.

As in Figure 2, the algorithm started with extraction of data from data logger with three main empirical data of $G, T_{\text {cell }}$ and $P_{\text {ac_actual }}$. Next, graph of $P_{\text {ac_actual }}$ and $P_{\text {ac_expected }}$ against $G$ has to be plotted. Applying (2) to calculate $P_{\text {ac_expected }}, k_{\text {dirt }}$ has to be initially estimated. $k_{\text {dirt }}$ is associated to the percentage of soiling factor caused by the accumulation of dust and dirt on the PV surface. The accumulation of dust and dirt eventually limiting the penetration of solar energy, hence the energy output become reduces [24]. To calculate the expected AC Power using (2), $k_{\text {dirt }}$ value will be varied as $0.8,0.85,0.9$ and 0.95. The graphs of $P_{a c_{-} \text {expected }}$ againts $P_{a c_{-} a c t u a l}$ for different values of $k_{\text {dirt }}$ were plotted and analyzed. From the graphs, the least percentage difference in gradient between actual and expected AC Power was chosen. Thus, the most probable value of $k_{\text {dirt }}$ was determined and substituted into (2) to calculate $P_{\text {ac_expected }}$.

The development of logic and decision trees considered the affected parameters that are related to the early detection fault. It requires historical data sets in order to learn the systematic performance behavior. A logic tree is a simple top-down approach that often solves a problem by breaking possible solutions into parts. In contrast, a decision tree is a flowchart-like tree structure that is used to detect the faulty from the normal ones. A decision tree consists of a root and internal (decision) nodes. Starting from the root node, each instance is split by the test to internal nodes, continues to the end terminal nodes to categorize either normal operation or fault condition [25].

An AR algorithm was developed as shown in Figure 4. AR was calculated for each five minutes data of both systems using (1). The graphs of AR in relationship to $G$ were plotted for both systems. The percentages of AR data below 0.9 were calculated for both graphs. The results were compared and analyzed. 


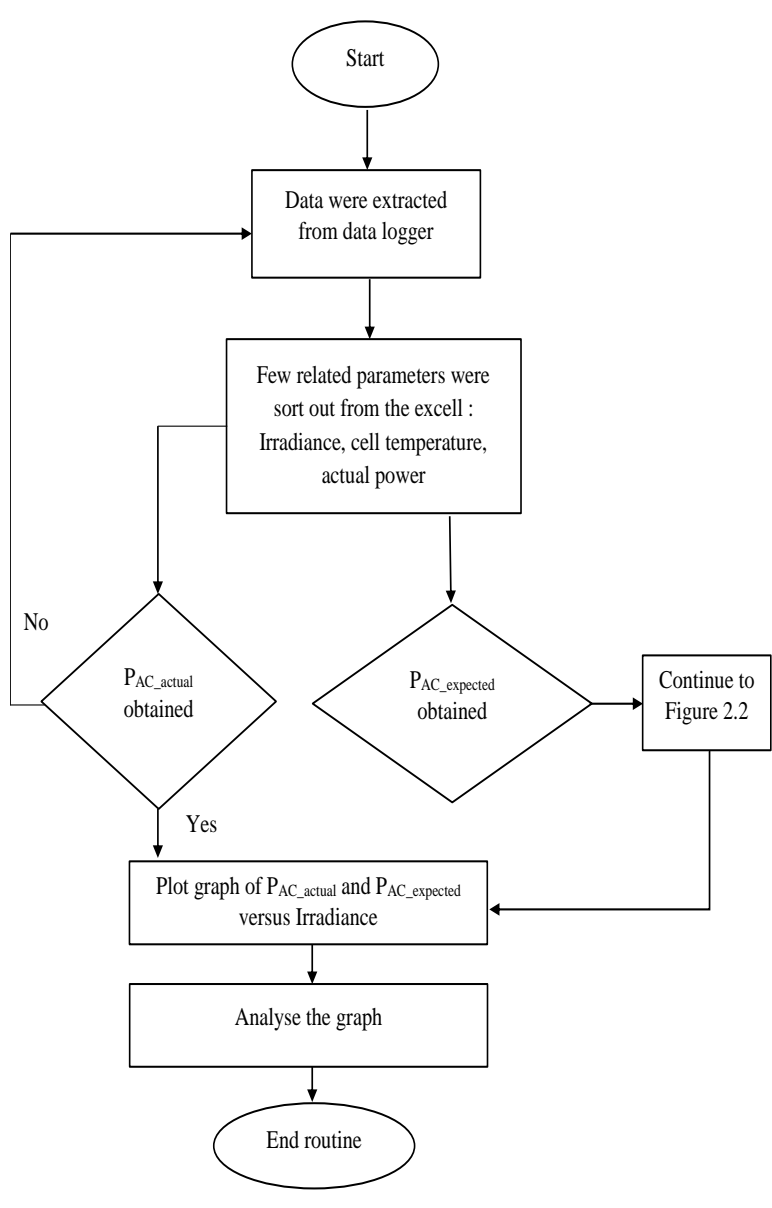

Figure 2. Logic tree for determination of $\mathrm{P}_{\mathrm{AC} \_ \text {actual }}$ and $P_{A C_{-} \text {expected }}$

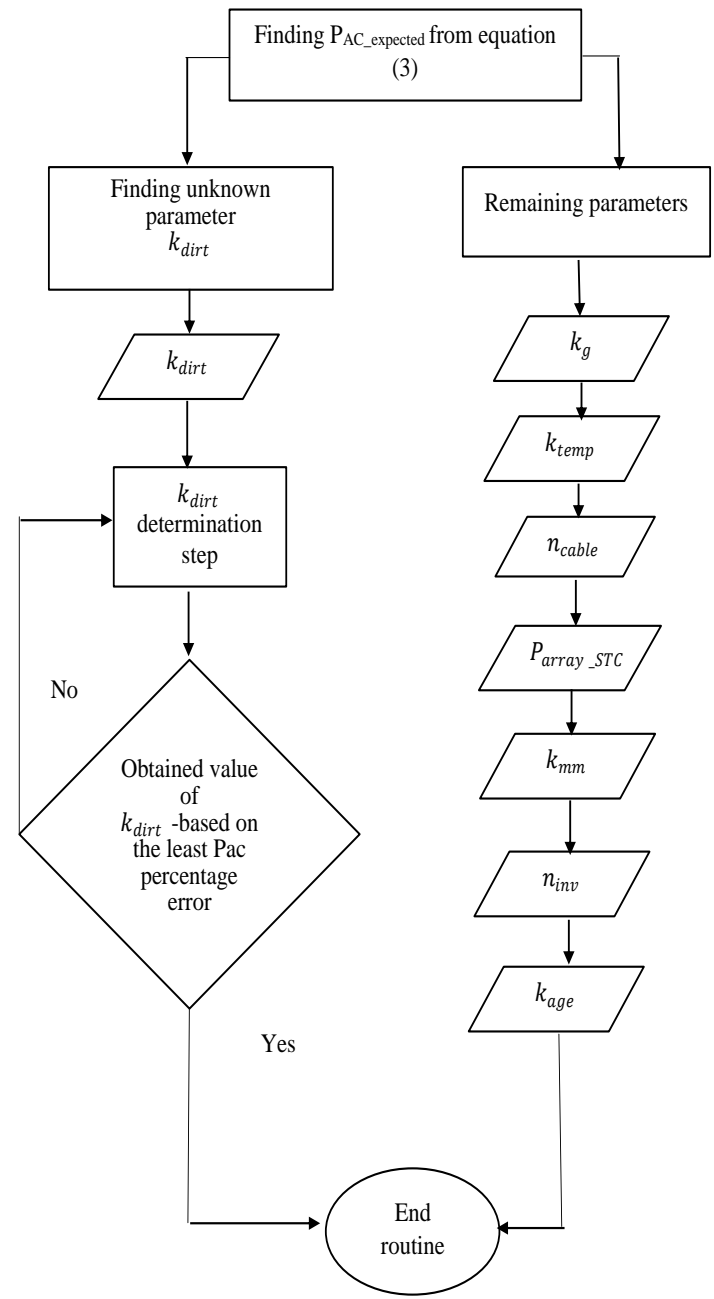

Figure 3. Logic tree for determination of $P_{A C_{-} \text {expected }}$

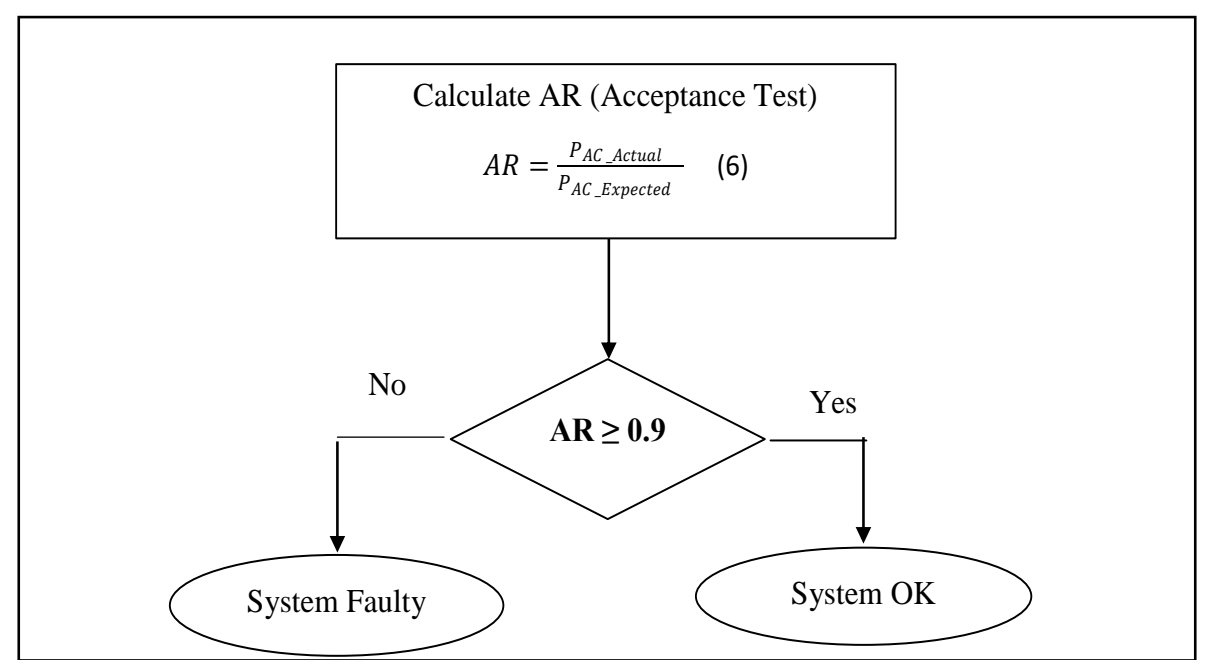

Figure 4. Logic tree for determination of AR 


\section{RESULTS AND ANALYSIS} AR analysis.

The results and analysis are divided into three sections of $\mathrm{k}_{\text {dirt }}$ determination, AC power analysis and

\section{1. $k_{\text {dirt }}$ Determination}

Since $k_{\text {dirt }}$ that appeared in (2) is an unknown parameter, therefore it has to be estimated. Graphs of actual and predicted AC power in relation to $G$ were plotted based on four most possible values of $k_{d i r}$. The estimation of the most effective $k_{\text {dirt }}$ was based on the comparison of the $\%$ difference between the gradient of the actual graph and the predicted graph. The least \% difference represents the most effective value of $k_{\text {dirt }}$. Hence, the results were summarized in Table 1.

Table 1. The Percentage Difference of Gradient for Actual and Expected AC Power with Different Value

\begin{tabular}{|c|c|c|c|c|}
\hline $\mathrm{k}_{\text {dirt }}$ value & 0.8 & 0.85 & 0.9 & 0.95 \\
\hline$\%$ difference & 9.15 & 3.48 & 2.2 & 7.88 \\
\hline
\end{tabular}

\subsection{AC Power Graphs}

The historical data of the related parameters of GCPV system was taken for a month duration of July 2018. For each individual PV system, the data was recorded for every 5 minutes interval. Based on Figure 5, the actual and expected powers are quite aligned as the values of $G$ are increasing. The actual data starts to show some spread from the expected trend line when $G$ reached about $200 \mathrm{~W} / \mathrm{m}^{2}$. The spread started to grow wider within the range of $300 \mathrm{~W} / \mathrm{m}^{2}$ to $1000 \mathrm{~W} / \mathrm{m}^{2}$. Besides that, the actual and expected gradients are 3.5174 and 3.5948 respectively. Both gradients show the percentage difference about $2.2 \%$ which is literally quite small.

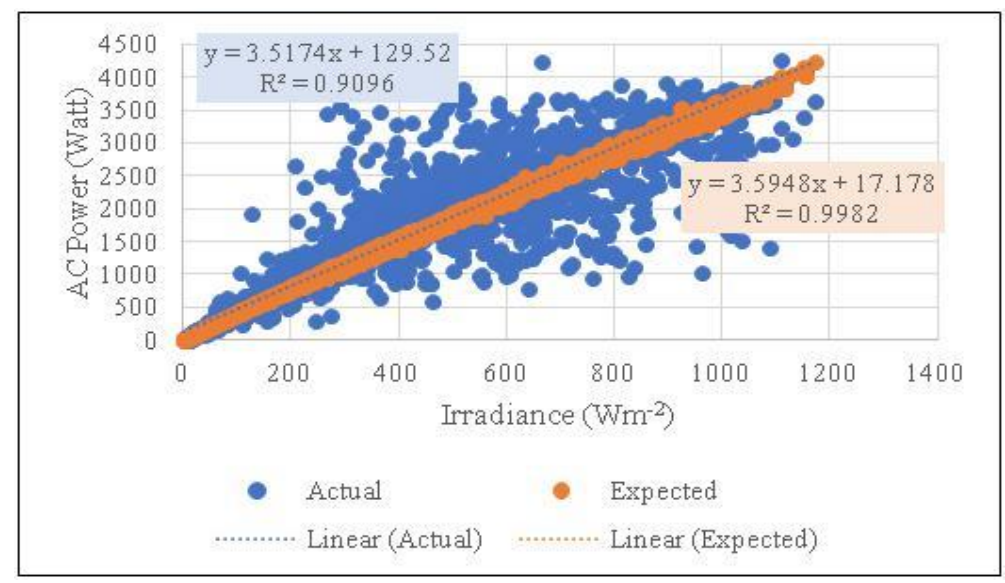

Figure 5. Actual and expected AC power versus in plane solar irradiance, $G$ for polycrystalline silicon PV module

Figure 6 clearly shows that both graphs are not aligned. When the $G$ increases, the actual data starts to move away from expected trend line. The most critical changes can be seen when $G$ reaches about $400 \mathrm{~W} / \mathrm{m}^{2}$ until maximum value. The gradient for actual graph is 3.5479 , while the gradient of the expected graph is 6.1134. By comparing these values of gradients, there is significant difference of $72.31 \%$. 


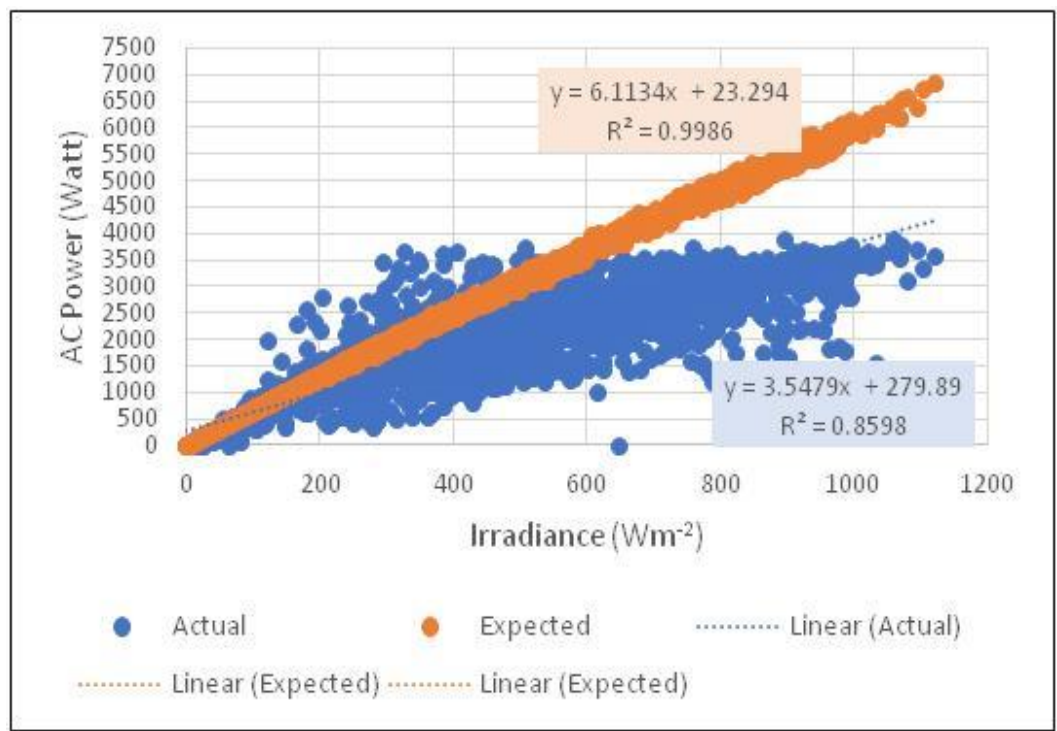

Figure 6. Actual and expected AC power versus in plane solar irradiance, $G$ for monocrystalline silicon PV module

\subsection{Acceptance Ratio (AR)}

Figure 7 shows values of $G$ from 0 to maximum and the corresponding ARs. The straight line is $\mathrm{AR}=0.9$. From the graph, it was observed that there are less data that lie lower than 0.9 compared to data that are greater than 0.9. Besides that, the data shows significant fluctuations within $200 \mathrm{~W} / \mathrm{m}^{2}$ until $400 \mathrm{Wm} \mathrm{m}^{2}$ of $G$ where AR could reach until 4.0.

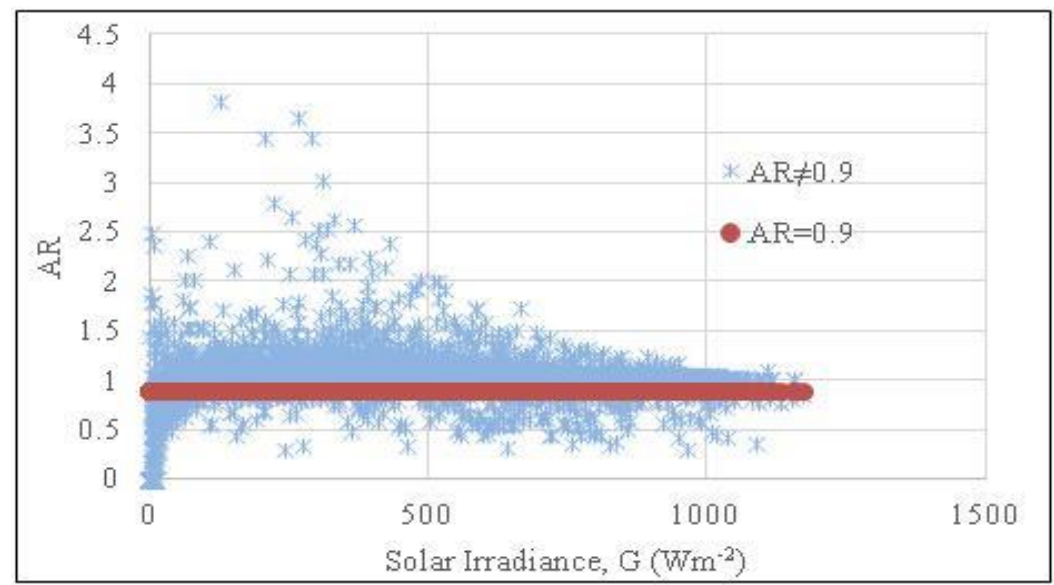

Figure 7. Acceptance Ratio (AR) versus in plane solar irradiance, $G$ for polycrystalline silicon PV module

On the other hand, Figure 8 shows that more data lies below than $\mathrm{AR}=0.9$ compared to greater than 0.9. During very low value of $G$, AR could reach until 0 . This is basically due to invalid value of output captured from the data logger. As regulated by SEDA, the relevant GCPV system testing has to be conducted when $G$ is greater than $350 \mathrm{~W} / \mathrm{m}^{2}$ [19]. Other than that, it was also observed that there were some fluctuations of data when $G$ was approaching $200 \mathrm{~W} / \mathrm{m}^{2}$ until $400 \mathrm{~W} / \mathrm{m}^{2}$. Overall graph shows a large amount of data lies below than 0.9 value of AR. 


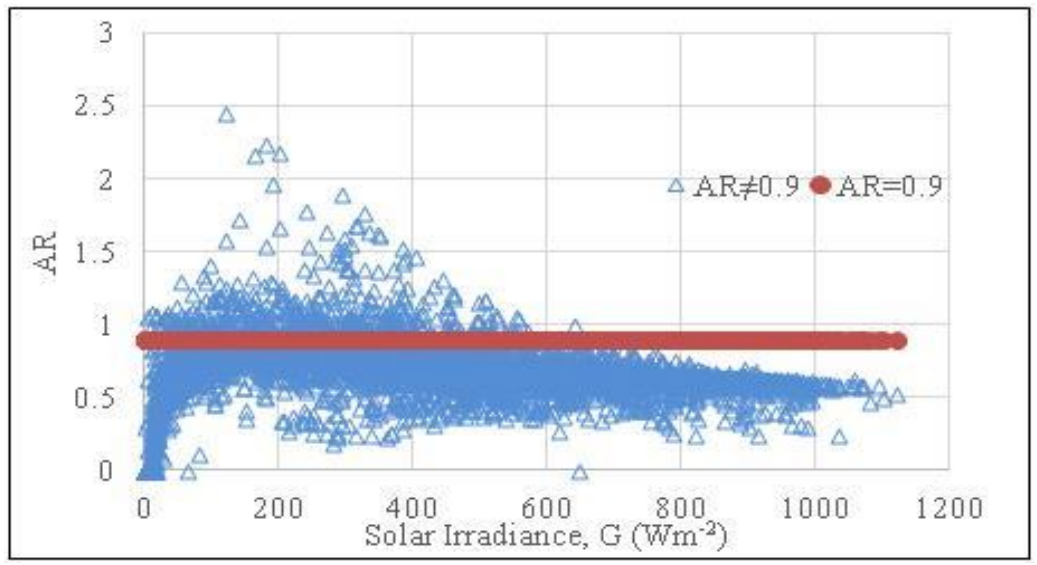

Figure 8. Acceptance Ratio (AR) versus in plane solar irradiance, $G$ for monocrystalline silicon PV module

Due to limited comprehensive studies on AR value as an early fault detection indicator, there were no exact threshold for AR, in order to decide whether the system is having fault or free fault. So, this study has been assuming, if the system having about more than half of data with AR $<0.9$, the PV system is having fault. This study has been comparing the AR values for both polycrystalline and monocrystalline silicon GCPV systems. Table 2 showed the amount of data in percentage for AR lower, equal and greater than 0.9 for both systems. This table shows that monocrystalline PV system contained about $93.38 \%$ of total data with value of AR lower than 0.9. From the percentage shown, where more than $50 \%$ of the AR lies below 0.9 , so it was proven that the monocrystalline PV system is having fault. Meanwhile, the polycrystalline PV system showed only about $31.4 \%$ of data with AR<0.9. This polycrystalline PV system is classified as having no fault and healthy.

Table 2. The Percentage of Data with AR Lies Lower, Greater and Equal than 0.9 for Polycrystalline and Monocrystalline Silicon PV System

\begin{tabular}{ccc}
\hline & \multicolumn{2}{c}{ AR Percentage $(\%)$} \\
\hline & Polycrystalline & Monocrystalline \\
$\mathrm{AR}<0.9$ (system faulty) & 31.4 & 93.38 \\
$\mathrm{AR} \geq 0.9$ (fault free) & 68.6 & 6.62 \\
\hline
\end{tabular}

\section{CONCLUSION}

This study has succeeded in presenting fault detection approach of GCPV system using two different case studies of polycrystalline and monocrystalline GCPV systems respectively. The percentage error of $P_{a c_{-} \text {actual }}$ to $P_{\text {ac_expected }}$ for the polycrystalline system is $2.2 \%$. However, the percentage error of $P_{a c \_a c t u a l}$ to $P_{\text {ac_expected }}$ for the monocrystalline system is $72.31 \%$. Comparison of the percentage error indicates that monocrystalline system is having fault. Applying AR indicator, the percentage of AR $<0.9$ is $31.4 \%$ for polycrystalline system. However, for monocrystalline system, the percentage of AR<0.9 is $93.38 \%$. This provides evidence that monocrystalline PV system is having fault. In conclusion, the fault analytical approaches of using AC Power and AR as two significant early fault indicators for GCPV system were proven to be significant and reliable.

\section{ACKNOWLEDGEMENTS}

The authors would like to thank Green Energy Research Center (GERC) and UiTM for funding this research under research grant of 600-IRMI/MyRA 5/3/BESTARI (017/2017).

\section{REFERENCES}

[1] M. Khatri and A. Kumar, "Two Variable Method for Fault Analysis in Grid Tied Solar Photovoltaic System," Int. J. Eng. Technol., vol. 9, no. 2, pp. 541-547, 2017.

[2] S. S. Raghuwanshi and V. Khare, "Sizing and Implementation of Photovoltaic Water Pumping System for Irrigation,” IAES Int. J. Artif. Intell., vol. 7, no. 1, pp. 54-62, 2018. 
[3] K. AbdulMawjood, S. S. Refaat, and W. G. Morsi, "Detection and Prediction of Faults in Photovoltaic Arrays: A Review," 2018 IEEE 12th Int. Conf. Compat. Power Electron. Power Eng. (CPE-POWERENG 2018), pp. 1-8, 2018.

[4] N. Muhammad, N. Z. Zakaria, S. Shaari, and A. M. Omar, "Fault Detection Approach in Pphotovoltaic System Using Mathematical Method Diagnosis," J. Fundam. Appl. Sci., 2018.

[5] K. Lenin, "Integrated Algorithm for Decreasing Active Power Loss," IAES Int. J. Artif. Intell., vol. 7, no. 1, pp. 33-41, 2018.

[6] T. Takashima, J. Yamaguchi, K. Otani, T. Oozeki, K. Kato, and M. Ishida, "Experimental Studies of Fault Location in PV Module Strings," Sol. Energy Mater. Sol. Cells, vol. 93, no. 6-7, pp. 1079-1082, 2009.

[7] E. Kaplani and S. Kaplanis, "Thermal Modelling and Experimental Assessment of The Dependence of PV Module Temperature on Wind Velocity and Direction, Module Orientation and Inclination," Sol. Energy, vol. 107, pp. 443-460, 2014.

[8] A. Chouder and S. Silvestre, "Automatic Supervision and Fault Detection of PV Systems Based on Power Losses Analysis," Energy Convers. Manag., vol. 51, no. 10, pp. 1929-1937, 2010.

[9] A. Chouder, S. Silvestre, B. Taghezouit, and E. Karatepe, "Monitoring, Modelling and Simulation of PV Systems using LabVIEW," Sol. Energy, vol. 91, pp. 337-349, 2013.

[10] Y. Yagi et al., "Diagnostic Technology and An Expert System for Photovoltaic Systems using The Learning Method," Sol. energy Mater. Sol. cells, vol. 75, no. 3-4, pp. 655-663, 2003.

[11] C. Mishra and D. L. Gupta, "Deep Machine Learning and Neural Networks: An Overview," IAES Int. J. Artif. Intell., vol. 6, no. 2, p. 66, 2017.

[12] S. Vergura, G. Acciani, and O. Falcone, "A Finite-Element Approach to Analyze the Thermal Effect of Defects on Silicon-Based PV Cells,” IEEE Trans. Ind. Electron., vol. 59, no. 10, pp. 3860-3867, 2012.

[13] S. R. Madeti and S. N. Singh, "A Comprehensive Study on Different Types of Faults and Detection Techniques for Solar Photovoltaic System,” Sol. Energy, vol. 158, no. October, pp. 161-185, 2017.

[14] M. A. Munoz, M. C. Alonso-García, N. Vela, and F. Chenlo, "Early Degradation of Silicon PV Modules and Guaranty Conditions," Sol. Energy, vol. 85, no. 9, pp. 2264-2274, 2011.

[15] M. A. Rodríguez-Blanco et al., "A Failure-Detection Strategy for IGBT Based on Gate-Voltage Behavior Applied to a Motor Drive System," IEEE Trans. Ind. Electron., vol. 58, no. 5, pp. 1625-1633, 2011.

[16] I. Bialasiewicz, Jan T. Senior Member, "Renewable Energy Systems with Photovoltaic Power Generators: Operation and Modeling," Ieee Trans. Ind. Electron., vol. 55, no. 7, pp. 2752-2758, 2008.

[17] S. Kim, K. Nam, H. Song, and K. Hogi, "Fault Diagnosis of a ZVS DC-DC Converter Based on DC-Link Current Pulse Shapes," IEEE Trans. Ind. Electron., vol. 55, no. 3, pp. 1491-1494, 2008.

[18] M. K. Alam, F. Khan, J. Johnson, and J. Flicker, "A Comprehensive Review of Catastrophic Faults in PV Arrays: Types, Detection, and Mitigation Techniques,” IEEE J. Photovoltaics, vol. 5, no. 3, pp. 982-997, 2015.

[19] "SEDA PORTAL." [Online]. http://seda.gov.my/?omaneg=00010100000001010101000100001000000000000000000000\&s=3096. [Accessed 02-Feb-2018]

[20] N. Muhammad, N. Z. Zakaria, S. Shaari, and A. M. Omar, "System Performance and Detectable Faults of a 10Year Old 1.1kWp GCPV System in Malaysia,” vol. 11, no. 1, pp. 10-17, 2017.

[21] M. Bressan and C. Alonso, "A New Method for Fault Detection and Identification of Shadows Based on Electrical Signature of Defects DC Power Analysis DC Measuring Box and PV System Description," 2015 17th Eur. Conf. Power Electron. Appl. (EPE'15 ECCE-Europe), pp. 1-8, 2015.

[22] Y. Chouay and M. Ouassaid, "An Intelligent Method for Fault Diagnosis in Photovoltaic Systems," Proc. 2017 Int. Conf. Electr. Inf. Technol. ICEIT 2017, vol. 2018-Janua, pp. 1-5, 2018.

[23] Malaysia Deparment of Standards, "IEC61724, Photovoltaic System Performance Monitoring- Guidelines for Measurement, Data Exchange and Analysis." 2010.

[24] W. J. Jamil, H. Abdul Rahman, S. Shaari, and Z. Salam, "Performance Degradation of Photovoltaic Power System: Review on Mitigation Methods," Renew. Sustain. Energy Rev., vol. 67, pp. 876-891, 2017.

[25] Y. Zhao, L. Yang, B. Lehman, J.-F. De Palma, J. Mosesian, and R. Lyons, "Decision Tree-Based Fault Detection and Classification in Solar Photovoltaic Arrays," 2012 Twenty-Seventh Annu. IEEE Appl. Power Electron. Conf. Expo., pp. 93-99, 2012.

\section{BIOGRAPHIES OF AUTHORS}

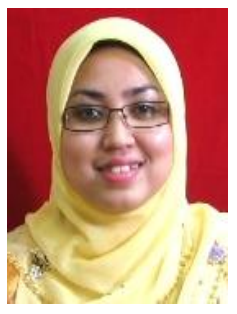

N. Muhammad received her M. Sc degree in June 2011 at the Universiti Kebangsaan Malaysia in Energy Technology program. Since October 2008 until now she is a physics lecturer at the Department of Physics and Material Sciences, Faculty of Applied Sciences, Universiti Teknologi MARA. She is now pursuing her PhD degree in Universiti Teknologi MARA focusing on the study of failure detection of PV systems and their modeling and analysis by using algorithm and threshold-based method. Another research activity concerning the failure detection by development of MATLAB based software that allows failure detection using specific thresholdbased value generated from PV system sites data in Malaysia. 

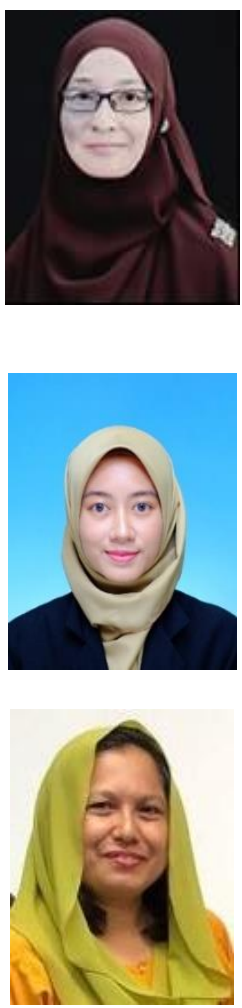

H. Zainuddin received the B.Sc. degree in Physics in 2000 and M. Sc in Photovoltaics in 2003, both from Universiti Kebangsaan Malaysia. She obtained her Ph. D from Universiti Teknologi MARA still in the area of Photovoltaic in 2014. She did her Ph. D internship at Austrian Institute of Technology in Vienna. Her specialization area are PV field testing, design of grid-connected PV (GCPV) system, design of off-grid PV (OGPV) system, mathematical and computational modeling (linear, multiple linear and artificial intelligent) and PV system fault detection. She obtained her certificate of competency in GCPV and OGPV from SEDA Malaysia in 2014 and 2018 respectively. Her current position is Senior Lecturer in Universiti Teknologi MARA (UiTM).

E. Jaaper started her degree in Physics in September 2016 at Universiti Teknologi MARA, Shah Alam. During her fourth semester, she went to Hospital Universiti Kebangsaan Malaysia (HUKM) in Cheras, Kuala Lumpur for her Internship at Radiology Department. She has just completed her final year project in Solar PV area with title An Early Fault Detection Approach in Grid-connected Photovoltaic (GCPV) System.

Z. Idrus received her degree in Computer Science from Creighton University, USA in 1993 and the MSc. Degree from Universiti Kebangsaan Malaysia, Malaysia. Later she pursued her PhD and graduated from Universiti Teknologi MARA, Malaysia in 2015. She is a senior lecture at Faculty of Computer and Mathematical Sciences, Universiti Teknologi MARA, Malaysia. Her current research includes data visualization, data analytics, computer support collaborative work and web technology. Her interest also include machine learning covering wide area of domains such as solar energy, underground tank, apparel as well as fault detection through data profiling and visualization. 